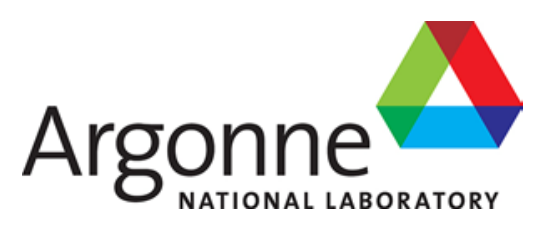

ANL-14/14

\title{
Development of Highly Selective Oxidation Catalysts by Atomic Layer Deposition
}

Energy Systems Division 


\title{
About Argonne National Laboratory
}

Argonne is a U.S. Department of Energy laboratory managed by UChicago Argonne, LLC under contract DE-AC02-06CH11357. The Laboratory's main facility is outside Chicago, at 9700 South Cass Avenue, Argonne, Illinois 60439. For information about Argonne and its pioneering science and technology programs, see www.anl.gov.

\section{DOCUMENT AVAILABILITY}

Online Access: U.S. Department of Energy (DOE) reports produced after 1991 and a growing number of pre-1991 documents are available free via DOE's SciTech Connect (http://www.osti.gov/scitech/)

\author{
Reports not in digital format may be purchased by the public from the \\ National Technical Information Service (NTIS): \\ U.S. Department of Commerce National \\ Technical Information Service 5301 \\ Shawnee Rd \\ Alexandra, VA 22312 \\ www.ntis.gov \\ Phone: (800) 553-NTIS (6847) or (703) 605-6000 \\ Fax: (703) 605-6900 \\ Email: orders@ntis.gov
}

\author{
Reports not in digital format are available to DOE and DOE contractors from the \\ Office of Scientific and Technical Information (OSTI): \\ U.S. Department of Energy \\ Office of Scientific and Technical Information \\ P.O. Box 62 \\ Oak Ridge, TN 37831-0062 \\ www.osti.gov \\ Phone: (865) 576-8401 \\ Fax: (865) 576-5728 \\ Email: reports@osti.gov
}

This report was prepared as an account of work sponsored by an agency of the United States Government. Neither the United States Government nor any agency thereof, nor UChicago Argonne, LLC, nor any of their employees or officers, makes any warranty, express or implied, or assumes any legal liability or responsibility for the accuracy, completeness, or usefulness of any information, apparatus, product, or process disclosed, or represents that its use would not infringe privately owned rights. Reference herein to any specific commercial product, process, or service by trade name, trademark, manufacturer, or otherwise, does not necessarily constitute or imply its endorsement, recommendation, or favoring by the United States Government or any agency thereof. The views and opinions of document authors expressed herein do not necessarily state or reflect those of the United States Government or any agency thereof, Argonne National Laboratory, or UChicago Argonne, LLC. 


\section{Development of Highly Selective Oxidation Catalysts by Atomic Layer Deposition}

Project Number FWP 49055; CPS Agreement 17784

Jeffrey W. Elam, Project Manager

Energy Systems Division, Argonne National Laboratory

prepared by

Northwestern University

Ineos Technologies, LLC

Project team member organizations:

DOE-EERE, Northwestern University, Ineos Technologies, LLC

August 18, 2014 


\section{FINAL REPORT}

Project Title: $\quad$ Development of Highly Selective Oxidation Catalysts by Atomic Layer Deposition

Date of Report: $\quad$ August 18, 2014

Recipient: $\quad$ Argonne National Laboratory

9700 S. Cass Avenue

Argonne, Illinois 60439

Project Number: $\quad$ FWP 49055

HQ CPS 11435

Subcontractors: Northwestern University

Other Partners: Ineos Technologies, LLC

Contact: Jeffrey W. Elam, 630-252-3520, jelam@anl.gov

Project Team: $\quad$ DOE-HQ: Dickson Ozokwelu, 202-586-8501

Northwestern University: Peter Stair

Ineos: Gerry Zajac

\section{Project Objective:}

The goal of the project is to develop new techniques for the manufacture of catalysts by atomic layer deposition (ALD) for the selective oxidative dehydrogenation of alkanes, for example, ethane to ethylene, propane to propylene, and butane to butadiene. The specific project objective is to demonstrate the catalyst manufacturing techniques by developing, characterizing, testing, and evaluating new catalysts for the selective oxidative dehydrogenation of alkanes on existing catalytic substrates in conventional reactors and in single-pass catalytic reactors utilizing AAO/ALD catalytic membranes.

\section{Background:}

The domestic chemical industry has identified improved separation and catalytic processes as a high priority research need for improving the energy efficiency of hydrocarbon processing. Recent advances at Argonne National Laboratory both in material synthesis techniques and in computational studies of these techniques on supported vanadate catalyst systems suggest that new efficient and more specific catalysts can be developed. The material synthesis techniques have been verified by the production of uniquely specific catalysts for the oxidative dehydrogenation reaction of cyclohexane to cyclohexene, resulting in increased product yield and improved product selectivity. In response to a solicitation from the Industrial Technology Program, Argonne National Laboratory and its partners, Northwestern University (Center for Catalysis and Surface Science, and Institute for Environmental Catalysis) and Ineos 
Technologies (formerly BP Amoco Chemicals), propose to develop new catalytic synthesis techniques. Successful completion of this project will advance the state-of-the-art, increase the understanding, and accelerate the development of highly selective catalytic materials for the domestic chemical industry. Successful implementation of the anticipated results of this project will result in significant energy, environmental, and economic benefits.

\section{ALD Process Development}

Figure 1 illustrates the principle synthetic concept that motivated this project. By depositing a series of ALD coatings on a substrate, we can individually tune the physical and chemical properties of the substrate to generate a catalyst that is highly selective and active, and combines both catalytic and separations functions in a single unit. In this example, the anodic aluminum oxide (AAO) membrane with intrinsic $40 \mathrm{~nm}$ pores is first coated by $\mathrm{ALD}$ with $\mathrm{Al}_{2} \mathrm{O}_{3}$ to uniformly shrink the pore size to $10 \mathrm{~nm}$ to alter the transport/filtering properties. Next, $\sim 0.5 \mathrm{~nm} \mathrm{ALD} \mathrm{TiO}{ }_{2}$ is deposited to act as the catalytic support layer. Finally, a

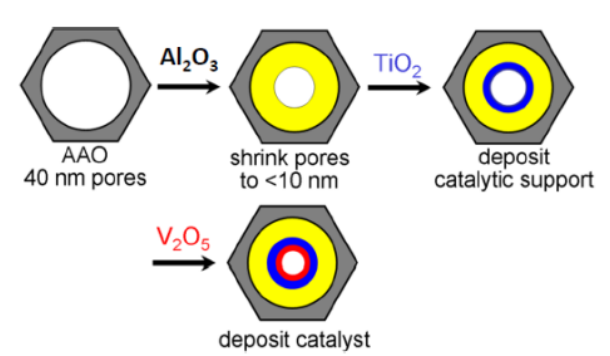

Figure 1: ALD synthesis of nanostructured catalyst using AAO membrane as template for growth. single cycle of ALD $\mathrm{V}_{2} \mathrm{O}_{5}$ is performed to deposit isolated $\mathrm{VO}_{\mathrm{x}}$ species on the surface to serve as the active catalyst.

To synthesize and evaluate the selective oxidative dehydrogenation (ODH) catalysts in this project, we first had to develop new ALD processes for depositing the necessary catalytic materials: silica, vanadia, niobia, molybdenum oxide, and tungsten oxide. These processes had to be compatible with the high surface area substrates required for effective catalysts. Moreover, we had to develop methodologies for coating and characterizing these high surface area substrates including mesoporous granular materials such as silica gel, and the nanoporous AAO membranes. These development activities will be detailed in the following sub-sections. Our primary focus was on vanadia catalysts given their high activity for ODH. In addition, we pursued mixed-metal ( $\mathrm{V}-\mathrm{Nb}-\mathrm{Mo}$ and $\mathrm{V}-\mathrm{Nb}-\mathrm{W}$ ) catalysts based on the high selectivity demonstrated by these materials for ethane $\mathrm{ODH}$.

\subsection{Silica ALD}

The ALD of silica $\left(\mathrm{SiO}_{2}\right)$ was needed in order to coat the convert the native alumina surface of the AAO membranes into $\mathrm{SiO}_{2}$ to be used as the support layer for the subsequent deposition of the vanadia and mixed-metal catalysts. We performed experiments examining improved methods for preparing $\mathrm{SiO}_{2}$ films by ALD. The existing method that uses alternating $\mathrm{SiCl}_{4} / \mathrm{H}_{2} \mathrm{O}$ exposures suffers from several limitations including the need for high deposition temperatures of $400^{\circ} \mathrm{C}$, very large reactant exposures as well as etching and corrosion problems from the $\mathrm{SiCl}_{4}$ precursor and the $\mathrm{HCl}$ byproduct. The improved method utilized alternating exposures to tris-dimethylamino silane $\left(\mathrm{SiH}\left(\mathrm{N}\left(\mathrm{CH}_{3}\right)_{3}\right)\right.$ and ozone, $\mathrm{O}_{3}$. In situ measurements performed using a quartz crystal microbalance (QCM) demonstrated self-limiting growth at $200^{\circ} \mathrm{C}$ using reactant exposures $\sim 10^{3}$ times lower than with $\mathrm{SiCl} / \mathrm{H}_{2} \mathrm{O}$. The growth 
was self-limiting and showed a modest growth rate of $\sim 0.23 \AA$ /cycle using exposure times $>6 \mathrm{~s}$ for the $\mathrm{SiH}\left(\mathrm{N}\left(\mathrm{CH}_{3}\right)_{3}\right.$ and $5 \mathrm{~s}$ for the $\mathrm{O}_{3}$. Although we were successful in developing this $\mathrm{SiO}_{2}$ ALD process, we elected later in the project to use $\mathrm{Nb}_{2} \mathrm{O}_{5}$ as the support layer for the vanadia catalyst and as a consequence we did not ultimately utilize the $\mathrm{SiO}_{2} \mathrm{ALD}$ for catalyst synthesis.

\subsection{Vanadium Oxide ALD}

Vanadium oxide $\left(\mathrm{V}_{2} \mathrm{O}_{5}\right)$ ALD was accomplished using alternating exposures to vanadium (V) trisisopropoxide (VOTP) and hydrogen peroxide $\left(\mathrm{H}_{2} \mathrm{O}_{2}\right)$. QCM measurements showed self-limiting growth at $\sim 0.45 \AA$ A cycle using a deposition temperature of $100^{\circ} \mathrm{C}$ and exposure times of $>0.25 \mathrm{~s}$ for the $\mathrm{H}_{2} \mathrm{O}_{2}$ and $>0.25 \mathrm{~s}$ for the VOTP (Figure 2). These studies utilized a vaporization temperature for the VOTP of $45^{\circ} \mathrm{C}$. It was also possible to deposit the vanadia using $\mathrm{H}_{2} \mathrm{O}$ in place of the $\mathrm{H}_{2} \mathrm{O}_{2}$, but in this case the growth rate was only $\sim 0.32$ Å/cycle. These observations were confirmed by ex situ spectroscopic ellipsometry, scanning profilometry, and scanning electron microscopy measurements for films prepared using 50-2000 $\mathrm{V}_{2} \mathrm{O}_{5}$ ALD cycles which revealed a growth rate of 0.41 Åcycle in good agreement with the QCM. We established that the growth was constant over the range of deposition temperatures of $70-150^{\circ} \mathrm{C}$. At higher temperatures, the growth rate increased dramatically due to thermal decomposition of the VOTP precursor. The films were smooth and amorphous as deposited (0.33 nm RMS roughness for $800 \mathrm{~nm}$ film) but crystallized upon annealing above $-200^{\circ} \mathrm{C}$. Using in situ QCM we confirmed that the ALD $\mathrm{V}_{2} \mathrm{O}_{5}$ proceeded promptly and without any apparent nucleation delay on ALD $\mathrm{TiO}_{2}$ surfaces prepared in situ using alternating exposures to $\mathrm{TiCl}_{4}$ and $\mathrm{H}_{2} \mathrm{O}_{2}$.

We also examined an alternative precursor for the $\mathrm{V}_{2} \mathrm{O}_{5}$ ALD, bis-pentamethyl cyclopentadienyl vanadium (II), or $\mathrm{V}\left(\mathrm{Me}_{5} \mathrm{Cp}\right)_{2}$ which had been custom-synthesized by the group of Tobin Marks at Northwestern University. We found the growth to be very similar to that of the VOTP, with a growth rate of $0.4 \AA$ \&cycle at a deposition temperature of $120^{\circ} \mathrm{C}$. However, the $\mathrm{V}\left(\mathrm{Me}_{5} \mathrm{Cp}\right)_{2}$ required a higher vaporization temperature of $100^{\circ} \mathrm{C}$ and longer exposure times of $>2 \mathrm{~s}$ due to the lower vapor pressure of this compound versus the VOTP. For these reasons, we elected to proceed with the VOTP for the remainder of the project. 


\subsection{Niobium Oxide ALD}

An ALD process for $\mathrm{Nb}_{2} \mathrm{O}_{5}$ was developed using alternating exposures to niobium $(\mathrm{V})$ ethoxide $\left(\mathrm{Nb}(\mathrm{OEt})_{5}\right)$ and either $\mathrm{H}_{2} \mathrm{O}_{2}$ or $\mathrm{H}_{2} \mathrm{O}$. These studies utilized a vaporization temperature for the $\mathrm{Nb}(\mathrm{OEt})_{5}$ of $110^{\circ} \mathrm{C}$ and a growth temperature of $200^{\circ} \mathrm{C}$. In this case, both the $\mathrm{H}_{2} \mathrm{O}_{2}$ or $\mathrm{H}_{2} \mathrm{O}$ yielded a similar growth rate of 0.45 $\AA$ /cycle for the $\mathrm{Nb}_{2} \mathrm{O}_{5}$. The optimal timing sequence was determined using in-situ quartz crystal microbalance (QCM) measurements. These measurements also verified the self-limiting surface reactions for this system. Next, $\mathrm{Nb}_{2} \mathrm{O}_{5}$ films were deposited on flat, $\mathrm{Si}(100)$

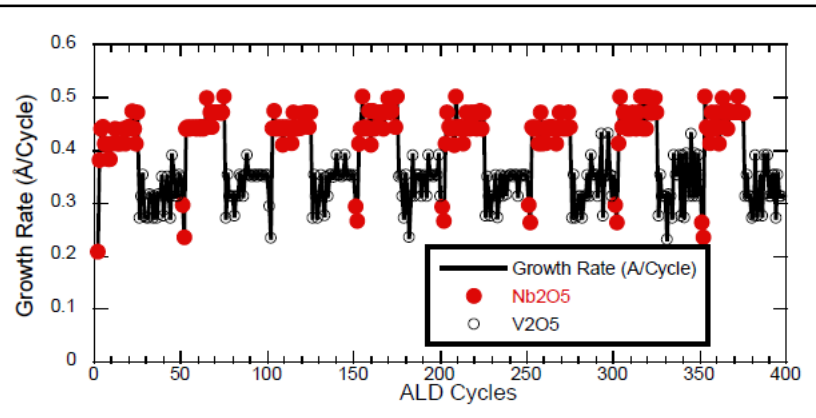

Figure 3: In situ QCM measurements performed during alternating growth of $\mathrm{V}_{2} \mathrm{O}_{5}$ and $\mathrm{Nb}_{2} \mathrm{O}_{5}$ ALD films. These data indicate that the $\mathrm{V}_{2} \mathrm{O}_{5}$ grows readily on the $\mathrm{Nb}_{2} \mathrm{O}_{5}$ and vice versa, as expected given that the ALD surface chemistries for these two materials are very similar.

surfaces and analyzed using ellipsometry, SEM and energy-dispersive $x$-ray analysis (EDAX) to determine the film thickness, surface morphology and chemical composition, respectively. In addition to the pure $\mathrm{Nb}_{2} \mathrm{O}_{5}$ films, we also studied the ALD of $\mathrm{Nb}_{2} \mathrm{O}_{5} / \mathrm{V}_{2} \mathrm{O}_{5}$ mixed oxide films using in-situ QCM, ellipsometry and EDAX measurements (Figure 3). These analyses confirmed that we can deposit these mixed-metal oxides with atomic-level control over both film thickness and stoichiometry. We deposited both $\mathrm{Nb}_{2} \mathrm{O}_{5}$ and $\mathrm{V}_{2} \mathrm{O}_{5}$ films by ALD onto nanoporous anodic aluminum oxide (AAO) membranes by extending the exposure times of the precursors relative to those used for the flat $\mathrm{Si}(100)$ surfaces.

\subsection{Molybdenum oxide ALD}

We evaluated several precursors for the ALD of molybdenum oxide, $\mathrm{MoO}_{3}$. The first precursor that we tested was diethyl-benzyl Mo (Mo(EtBz) $\left.)_{2}\right)$, however we failed to observe self-limiting ALD using this compound. The second precursor was molybdenum(IV) oxide acetylacetonate $\left(\mathrm{MoO}_{2}(\mathrm{acac})_{2}\right)$. At a deposition temperature of $200^{\circ} \mathrm{C}$ and a vaporization temperature of $150^{\circ} \mathrm{C}$ and using $\mathrm{O}_{3}$ as the co-reactant, in situ QCM measurements showed a growth rate of -0.3-0.4 Å/cycle. Spectroscopic ellipsometric measurements of the $\mathrm{MoO}_{3}$ films deposited on silicon substrates using 10-300 ALD $\mathrm{MoO}_{3}$ cycles yielded a somewhat higher growth rate of 0.47

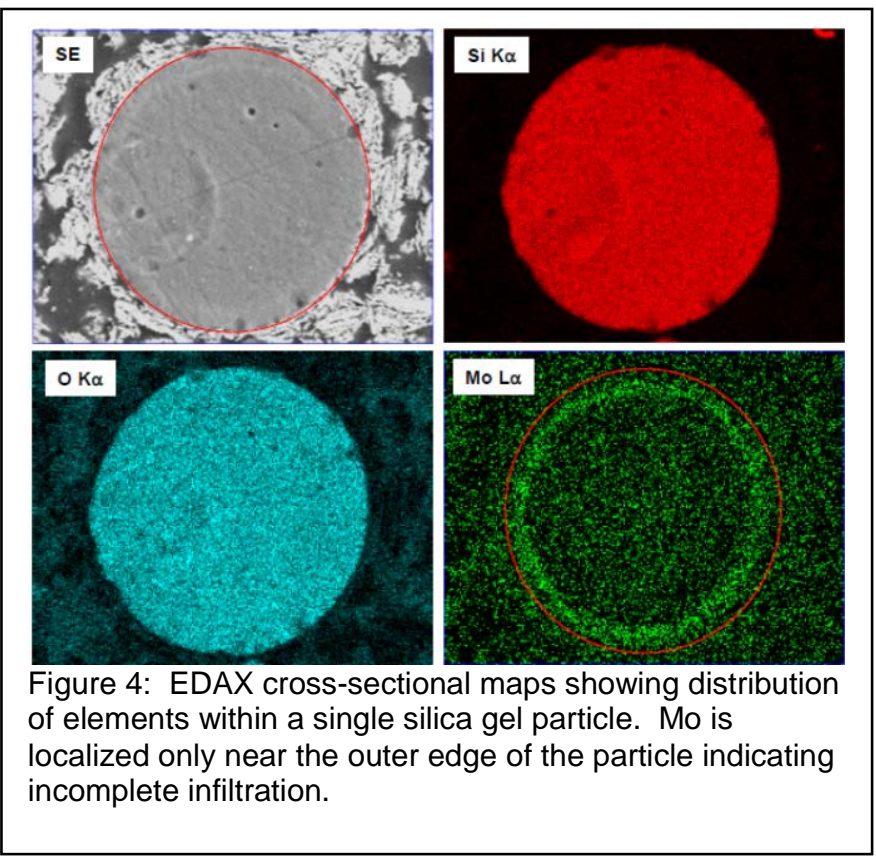


$\AA /$ cycle. However, the $\mathrm{MoO}_{3}$ growth was not found to be self-limiting, but rather the thickness increased steadily with increasing $\mathrm{MoO}_{2}(\mathrm{acac})_{2}$ exposure times. For this reason, we evaluated a third ALD $\mathrm{MoO}_{3}$ precursor, molybdenum(IV) oxide tetramethyl-heptanedionate, $\left(\mathrm{MoO}_{2}(\mathrm{thd})_{2}\right)$. At a deposition temperature of $210^{\circ} \mathrm{C}$ and a vaporization temperature of $180^{\circ} \mathrm{C}$, in situ QCM measurements showed mass uptake using either $\mathrm{H}_{2} \mathrm{O}, \mathrm{H}_{2} \mathrm{O}_{2}$, or $\mathrm{O}_{3}$ as the oxygen source but the largest growth rate was obtained using the $\mathrm{O}_{3}$. Next, $\mathrm{MoO}_{3}$ coatings were prepared on high surface area silica gel substrates and self-limiting growth was observed at $0.7 \mathrm{Wt} \% /$ cycle using the $100 \mathrm{~m}^{2} / \mathrm{g}$ substrate material as determined using X-ray fluorescence measurements. However, subsequent cross-sectional scanning electron microscopy with energy-dispersive analysis of X-rays (SEM-EDAX) revealed that only the outer $\sim 10$ micron perimeter of the 100 micron sized silica gel particles was coated (Figure 4). We believe the incomplete infiltration of the $\mathrm{MoO}_{3}$ into the mesoporous silica gel resulted from thermal decomposition of the $\mathrm{O}_{3}$ on the $\mathrm{MoO}_{3}$ surface. Due to these difficulties in achieving satisfactory conformal coatings of the $\mathrm{MoO}_{3}$, we elected to proceed with $\mathrm{WO}_{3}$ instead.

\subsection{Tungsten oxide ALD}

We pursued tungsten oxide $\left(\mathrm{WO}_{3}\right)$ ALD using the approach of first depositing metallic $W$ using alternating exposures to disilane $\left(\mathrm{Si}_{2} \mathrm{H}_{6}\right)$ and tungsten hexafluoride $\left(\mathrm{WF}_{6}\right)$ followed by calcining to form the oxide. In situ QCM measurements revealed the W ALD to be self-limiting over a range of deposition temperatures between $125-300^{\circ} \mathrm{C}$, and this finding was corroborated using ellipsometry, stylus profiling, and cross-sectional SEM measurements for ALD W films deposited on planar silicon substrates. The growth rate increased with increasing deposition temperature from $\mathrm{m}=3.1 \AA /$ cycle at $125^{\circ} \mathrm{C}$ to $\mathrm{m}=8.2 \AA /$ cycle at $300^{\circ} \mathrm{C}$ (Figure 5$)$. We found the conformality of the ALD $W$ films to be superb. We deposited uniform $W$ films inside of AAO membranes, carbon aerogels, and mesoporous silica gel substrates, and in all cases cross sectional SEM-EDAX measurements verified complete and uniform infiltration of these substrates by the ALD W

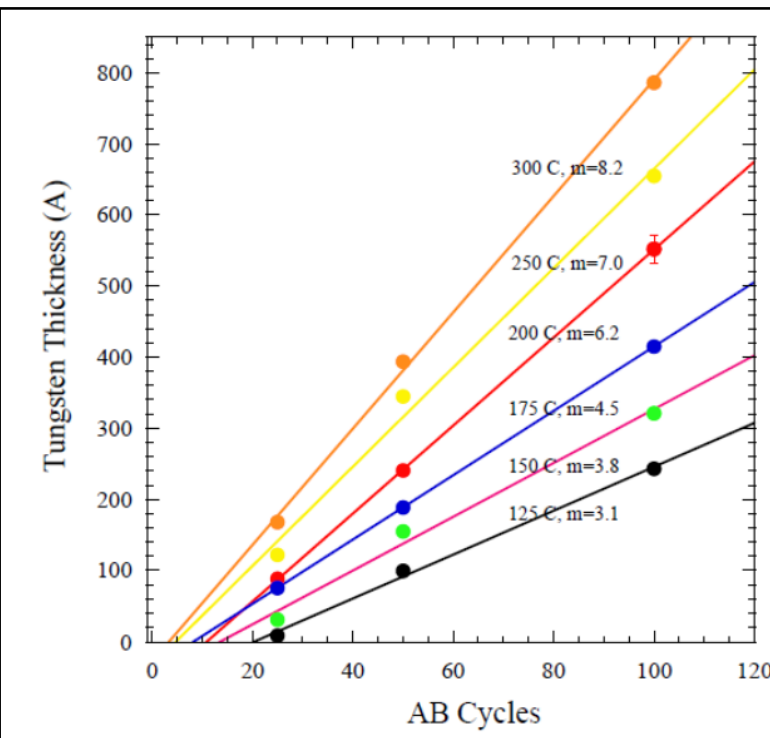

Figure 5: ALD tungsten thickness versus cycles as measured by ellipsometry for films prepared on silicon at different temperatures. ALD temperatures (in ${ }^{\circ} \mathrm{C}$ ) and growth rate $(\mathrm{m})$ for each trace are indicated.

films. We discovered that the post-deposition calcining to form the oxide had to be performed slowly and with care to avoid a thermal runaway condition caused by the exothermic tungsten oxidation reaction. By limiting the oxygen partial pressure to be only a few Torr, and performing the oxidation at temperatures below $100^{\circ} \mathrm{C}$, we found that the oxidation could be well-controlled.

Due to the inhibited growth of the W ALD on metal oxide surfaces, the W growth per cycle varied initially with the number of ALD W cycles performed, at least in the early stages of growth. For instance, using the same silica gel substrate with $100 \mathrm{~m}^{2} / \mathrm{g}$ specific surface area, 
the $\mathrm{W}$ loading resulting from 1, 2, and $3 \mathrm{~W}$ ALD cycles was 12, 47, and $110 \mathrm{wt} \%$, respectively, on an $\mathrm{Al}_{2} \mathrm{O}_{3}$ surface, versus 2,11 , and $25 \mathrm{wt} \%$, respectively, on a $\mathrm{Nb}_{2} \mathrm{O}_{5}$ surface. This behavior was reproducible, and consequently it was possible to control precisely the $\mathrm{W}$ loading if the nucleation behavior was taken into account.

\subsection{Conformal ALD Coating of AAO Membranes}

The AAO membranes were prepared using a two-step anodization process with high purity aluminum disks carried out in $0.3 \mathrm{M}$ oxalic acid at a constant potential of 40 volts, resulting in $40 \mathrm{~nm}$ pores with an average pore to pore separation of $110 \mathrm{~nm}$. The thickness (pore length) of the AAO membranes, $\sim 70 \mu \mathrm{m}$ in this case, was controlled by the duration of the second-step anodization and was verified using cross-sectional SEM measurements. The aluminum disk were masked during fabrication to preserve an aluminum border around the perimeter of the AAO discs. This enabled the membrane to be sealed in the catalyst testing reactor using commercial compression fittings (VCR glands). Before any catalyst was loaded, the AAO pores were coated with at least $1 \mathrm{~nm}$ of $\mathrm{Al}_{2} \mathrm{O}_{3}$ to completely cover electrolyte impurities incorporated into the oxide material during anodization. The layerby-layer growth of alumina was achieved by alternatively exposing the AAO substrates to trimethyl aluminum and water for 8 cycles using a quasi-static reactor operation mode in which the reactor is pumped down to 0.1 Torr after each dose and purge. The ALD

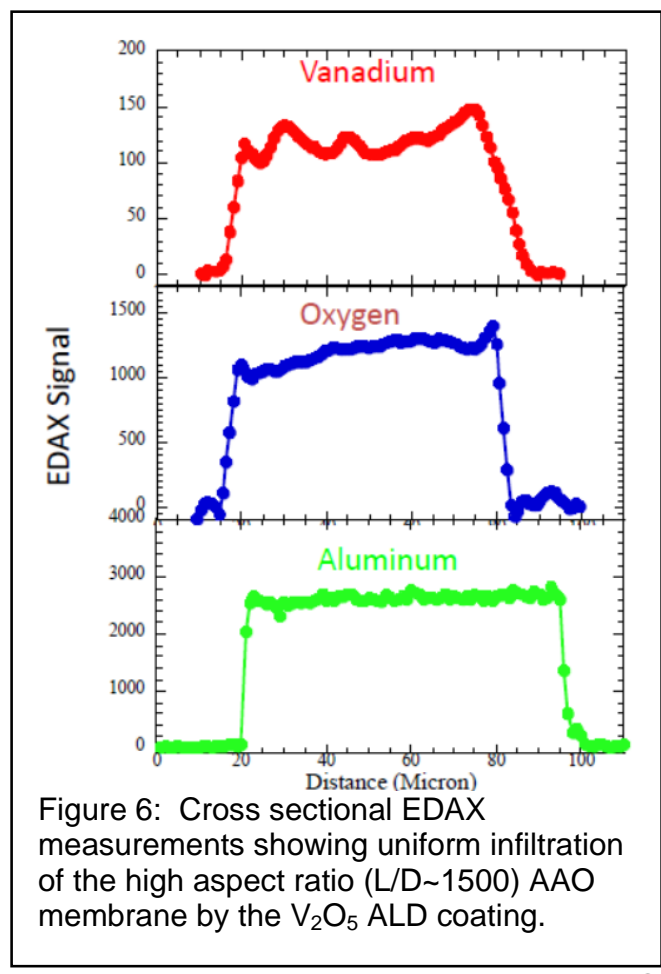
precursor partial pressures and exposures times were increased when coating the AAO membranes as compared to coating planar substrates in order to facilitate the gaseous diffusion into the very high aspect ratio AAO pores. Figure 6 shows cross-sectional EDAX measurements for the $\mathrm{V}, \mathrm{O}$, and $\mathrm{Al}$ following $\mathrm{ALD} \mathrm{V}_{2} \mathrm{O}_{5}$ in the AAO membrane. The relatively constant $V$ EDAX signal across the $\sim 70$ micron thickness of the AAO indicates uniform infiltration of the AAO.

In the course of preparing the ALD/AAO catalysts, we discovered a novel technique for depositing materials at controlled depths within porous substrates based upon the passivating effect produced by one precursor to prevent the adsorption of a second precursor. For example, a surface exposed to trimethyl aluminum is not reactive towards diethyl zinc. This effect, combined with Knudsen diffusion in which the precursor exposure times dictate the depth of penetration of the deposited layer, enables spatially controlled "stripe coating" within porous supports. We used this method to deposit stripes of $\mathrm{ZnO}, \mathrm{TiO}_{2}, \mathrm{~V}_{2} \mathrm{O}_{5}$, and $\mathrm{Nb}_{2} \mathrm{O}_{5}$ at specified depths within AAO membranes. The stripes were visualized by cross-sectional elemental mapping of the coated AAO membranes. The factors controlling the stripe locations and widths 
were identified by comparing the experimental results with the results of Monte Carlo simulations. This new technique opens up potential applications in sensors, separation devices, and multistep catalysts. For example, Figure 7 shows a stripe of $\mathrm{TiO}_{2}$ prepared at a depth of $\sim 20$ microns within a 70 micron thick AAO membrane. One potential application for this method to catalysis is that a series of stripes of different catalytic material could be prepared so as to effect an $A \rightarrow B \rightarrow C$ sequential catalytic conversion
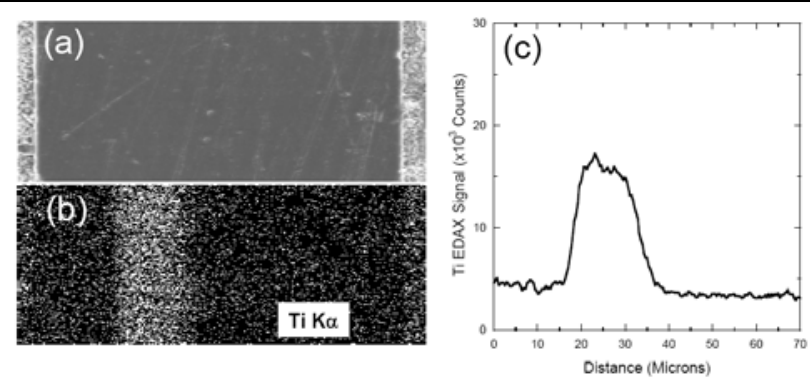

Figure 7: SEM secondary electron image (a) and EDAX elemental map for $\mathrm{Ti}(\mathrm{b})$ of AAO membrane following deposition of $\mathrm{TiO}_{2}$ internal stripe. (c) Linescan for $\mathrm{Ti}$ concentration showing location of $\mathrm{TiO}_{2}$ internal stripe. within a single membrane.

We used $\sim 1 \mathrm{~cm}$ AAO membranes for the development work in this project. However, we identified a commercial partner (Synkera, Inc.) capable of fabricating large area AAO membranes for scale-up. Figure 8 shows a photograph of an AxA inch AAO membrane fabricated by our parnter.

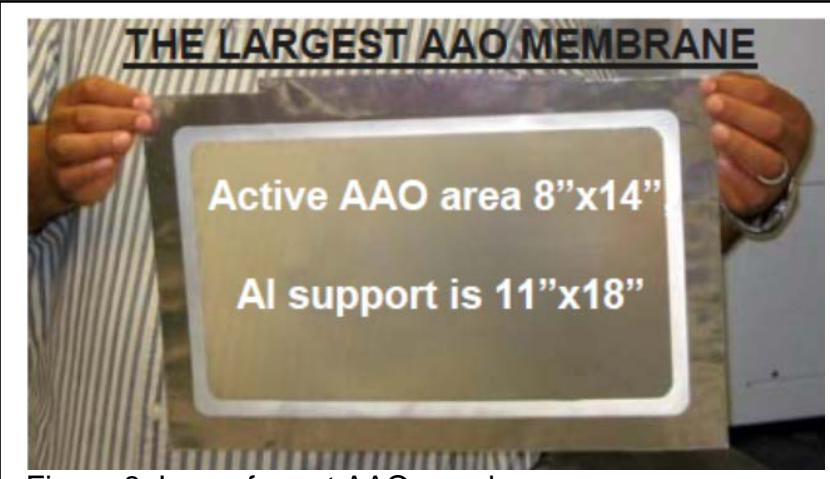

Figure 8: Large format AAO membrane.

\subsection{Conformal ALD Coating of Porous Powders}

Prior to the ALD coating in powders, fixtures were designed and fabricated to allow small quantities $(\sim 1 \mathrm{~g})$ of porous powders to be coated with catalytic layers inside of the existing ALD viscous flow reactors at Argonne. In addition, characterization facilities were commissioned. An Oxford instruments ED2000 X-ray fluorescence (XRF) spectrometer was acquired and installed in our ALD laboratory. This instrument was used to determine the composition of the ALD layers deposited on both flat test substrates as well as on the high surface area catalytic support powders and membranes. We used the XRF to verify the self-limiting growth of ALD ZnO monolayers on gram-quantities of high surface area silica powder. In addition, we used crosssectional SEM and EDAX measurements of individual silica particles to prove that the ZnO completely and uniformly infiltrates these silica supports. We have also used XRF to quantify the $\mathrm{V}_{2} \mathrm{O}_{5}$ coverages on AAO membranes. X-ray photoelectron spectroscopy (XPS) and 
inductively coupled plasma atomic absorption spectroscopy (ICP-AES) measurements were performed at Ineos on the silica powder coated materials. These measurements confirmed the anticipated loadings, and also identified possible contamination that may arise from the commercially obtained ALD precursors.

Our initial studies of ALD in the high surface area porous powders revealed that the optimized ALD process conditions developed for ALD growth on wafers and during QCM studies are not directly applicable. In order to better understand the interplay between process and reactor conditions on the ALD coating of highsurface area and high-aspect ratio substrates, a benchmarking study was performed on the silica gel catalyst support powders using the very well understood
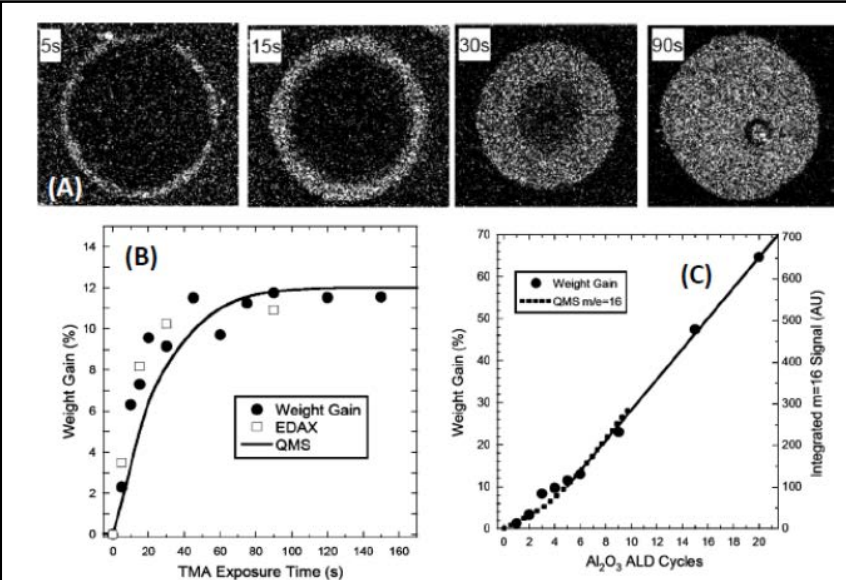

Figure 9: (a) Cross-sectional EDAX maps of Al in silica gel after $\mathrm{ALD} \mathrm{Al}_{2} \mathrm{O}_{3}$ coating illustrating that this porous material coats from the outside progressively inward with increasing exposure times; (b) Uptake measurements versus TMA exposure during $\mathrm{Al}_{2} \mathrm{O}_{3}$ ALD in silica gel showing saturation behavior; (c) weight gain versus number of $\mathrm{ALD} \mathrm{Al}_{2} \mathrm{O}_{3}$ cycles demonstrating linear growth. zinc oxide ALD process comprising the precursors diethyl zinc (DEZ) and $\mathrm{H}_{2} \mathrm{O}$. The ZnO study provides a benchmark for evaluating other ALD coatings onto the same powders. In particular a 3-cycle application of $\mathrm{DEZ} / \mathrm{H}_{2} \mathrm{O}$ onto a $100 \mathrm{~m}^{2} / \mathrm{g}$ silica gel yielded an $8.0 \%$ weight gain of $\mathrm{ZnO}$. Next, we coated commercial silica gel (Silicycle S10040M, $100 \mathrm{~m}^{2} / \mathrm{g}, 100$ micron particle size) using $\mathrm{ALD} \mathrm{Al}_{2} \mathrm{O}_{3}$ to characterize how ALD performs on these high aspect ratio, high surface area materials. Figure 9a shows EDAX elemental maps of the Al concentration taken from individual grains coated using TMA exposure times of $5,15,30$, and $90 \mathrm{~s}$. It is clear that the coating occurs from the outside of the particles first and progresses inward as the exposures approach saturation. Figure $9 \mathrm{~b}$ shows that the weight gain and the EDAX intensity both saturate at $\sim 70$ s exposure time, and this corresponds well to the predicted value based on the surface area of the silica gel and the TMA partial pressure. Figure 9c shows that the weight gain of the silica gel increases linearly with increasing $\mathrm{Al}_{2} \mathrm{O}_{3}$ ALD cycles as predicted for layer-bylayer coating in the limit where the silica gel pore size does not change significantly.

Using lessons learned from the benchmarking studies, a successful process for ALD vanadium oxide was developed where a $5.4 \%$ weight gain for a 3 -cycle exposure was observed on powders. Both of these values are consistent with growth rates observed for the same ALD reactants on flat substrates. For the $\mathrm{V}_{2} \mathrm{O}_{5}$ ALD using alternating exposures to VOTP and $\mathrm{H}_{2} \mathrm{O}_{2}$, we also observed saturating in the weight gain versus

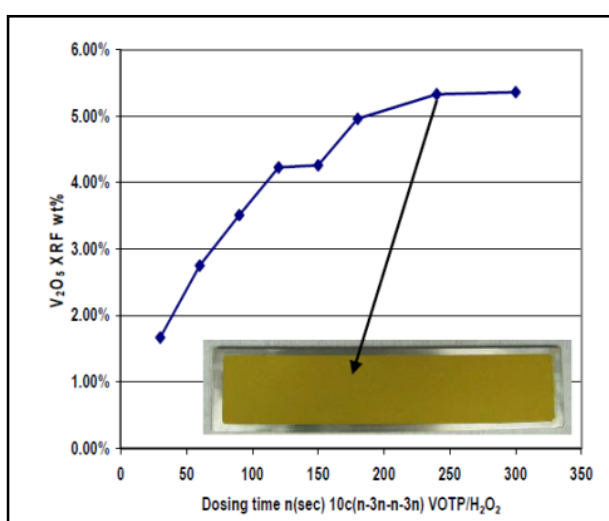

Figure 10: Uptake measurements versus VOTP and $\mathrm{H}_{2} \mathrm{O}_{2}$ exposure during $\mathrm{V}_{2} \mathrm{O}_{5}$ ALD in silica gel showing saturation behavior. Photo shows uniform coloration of the $\mathrm{V}_{2} \mathrm{O}_{5}$-coated silica gel at saturation. 
exposure times as illustrated in Figure 10. In this case, saturation required 250s, and this is a consequence of the lower vapor pressure for VOTP compared to TMA. The initially white silica gel powder became a uniform yellow color when saturation of the $\mathrm{V}_{2} \mathrm{O}_{5}$ ALD was achieved. For subsaturating exposures, the color was still uniform across the powder bed, but the shade was lighter. This behavior is consistent with the ALD coating occurring essentially uniformly on the entire powder bed, but with the infiltration occurring progressively into the individual particles with longer exposure times, analogous to the behavior shown in Fig. 9 for the ALD $\mathrm{Al}_{2} \mathrm{O}_{3}$ in the silica gel. Similarly, we achieved good saturation and uniform infiltration of the $\mathrm{S} 10040 \mathrm{M}$ silica gel powder using the alternating $\mathrm{Nb}(\mathrm{OEt})_{5} / \mathrm{H}_{2} \mathrm{O}$ exposures for $\mathrm{Nb}_{2} \mathrm{O}_{5}$ ALD as shown in Figure 11. Using 3 ALD $\mathrm{Nb}_{2} \mathrm{O}_{5}$ cycles, we found saturating loadings of $\sim 1 \mathrm{wt} \% \mathrm{Nb}_{2} \mathrm{O}_{5}$ using $\mathrm{Nb}(\mathrm{OEt})_{5}$ exposure times of $300 \mathrm{~s}$ (Fig. 11a). Moreover, cross sectional EDAX elemental mapping of the $\mathrm{Nb}$ revealed uniform infiltration of the high aspect ratio and high surface area silica gel substrate (Fig. 11b).

Finally, we synthesize ALD coatings of the mixed-metal catalyst materials inside of the silica gel nanoporous powder substrates. Using the processes for the ALD $\mathrm{Nb}_{2} \mathrm{O}_{5}$, $\mathrm{V}_{2} \mathrm{O}_{5}$, and $\mathrm{W}$ described above, we prepared a sample using all three processes in succession and subsequently analyzed the material using XRF measurements (Fig. 12). We found that the loadings of the $\mathrm{Nb}, \mathrm{W}$, and $\mathrm{V}$ were consistent with our expectations, thereby confirming our ability to synthesize complex, mixed-metal catalysts on high surface area powders using ALD.

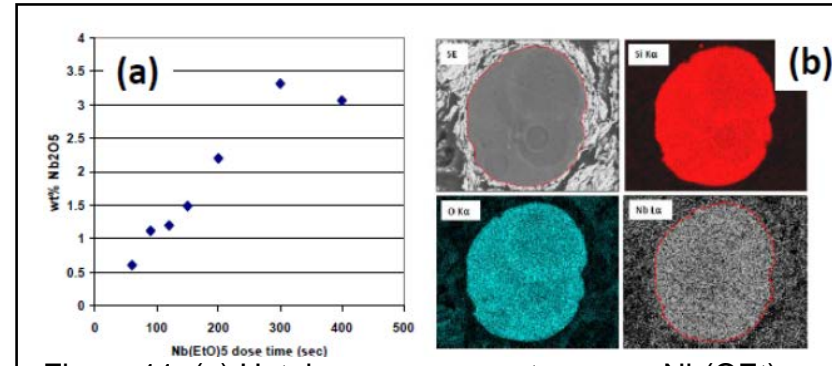

Figure 11: (a) Uptake measurements versus $\mathrm{Nb}(\mathrm{OEt})_{5}$ exposure during $\mathrm{Nb}_{2} \mathrm{O}_{5}$ ALD in silica gel showing saturation behavior. (b) EDAX cross sectional elemental maps showing uniform infiltration of the ALD $\mathrm{Nb}_{2} \mathrm{O}_{5}$.

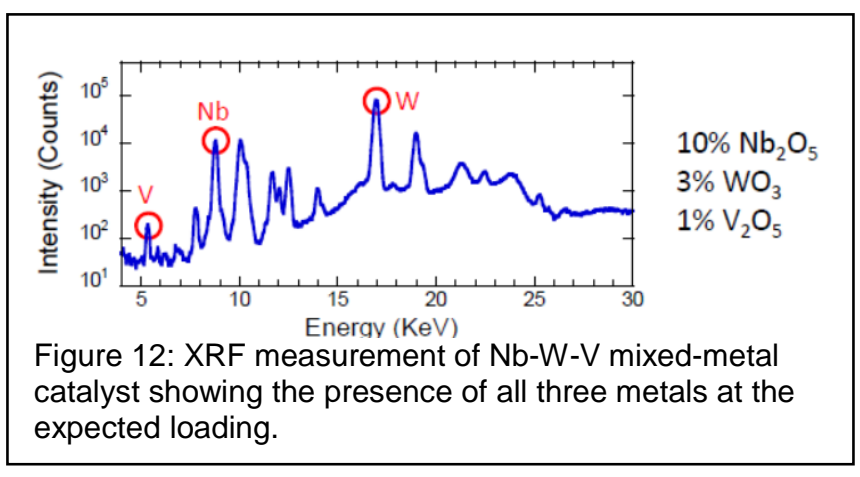

\section{Facilities and Equipment Development}

In addition to the ALD process development described in Section 1, there was significant facilities and equipment development required for this project in order to develop the necessary custom infrastructure to manufacture and test the catalysts.

\subsection{AAO Fabrication Facility}

Anodic aluminum oxide (AAO) membranes consist of a uniform array of hexagonal cells, extending from the surface through the width of the membrane. Generation of AAO membranes requires a series of electrochemical anodizations (30 volts max) to form the pores and chemical 
etchings to remove unwanted material. To facilitate catalyst testing in the AAO membranes, a facility was installed for producing batches of 8 membranes with an integral aluminum border to permit sealing of the catalyst membrane using VCR face-seal glands. In this way, the catalyst testing gas mixture can be forced to flow through the AAO pores without bypass. Fabrication of AAO membranes is an electrochemical process consisting of the following steps:

- Annealing of sample - e.g., at $500^{\circ} \mathrm{C}$ in a tube furnace in an argon atmosphere

- Electropolishing of sample - e.g., at $0^{\circ} \mathrm{C}$ in a perchloric acid / ethanol solution

- First anodization - e.g., at $3^{\circ} \mathrm{C}$ in an oxalic acid solution

- Removal of preliminary AAO - e.g., at $60^{\circ} \mathrm{C}$ in a chromic acid / phosphoric acid solution

- Second anodization (if necessary) - e.g., at $3^{\circ} \mathrm{C}$ in an oxalic acid solution

- First Etching - at room temp in a copper chloride / hydrochloric acid solution

- $\quad$ Second Etching (If necessary) - at $30^{\circ} \mathrm{C}$ in a phosphoric acid solution

- Chemical and/or microstructural Analysis

Figure 13 describes the AAO fabrication facility. The top right image shows the anodization bath and current source. The top left image shows the AAO fixture which is designed to accommodate 8 polished Al discs in separate anodization volumes. The bottom left image shows a photograph of the resulting AAO membrane retained in the integral aluminum sealing ring, and the bottom right image is an SEM micrograph of the AAO showing the $40 \mathrm{~nm}$ diameter pores in an hexagonal arrangement.

\subsection{Catalyst Testing System}

A Catalyst Test Station (CTS) was custom designed and built for the evaluation of powder and membrane catalysts in flowing gaseous reactions at atmospheric pressure and up to $650^{\circ} \mathrm{C}$ temperature (Figure 14). Catalyst Test System flows metered amounts of a mixture of hydrocarbon gases (methane, methanol, propane or ethane) and oxidizers (water or oxygen) using an Ar carrier gas through a heated $\left(100-650^{\circ} \mathrm{C}\right)$ reactor fixture containing up to 1.0 gram of a catalyst

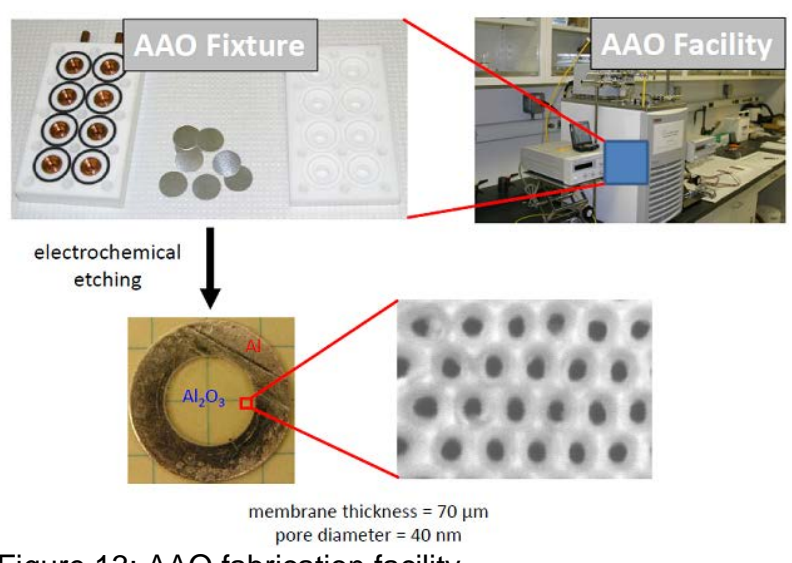

Figure 13: AAO fabrication facility.

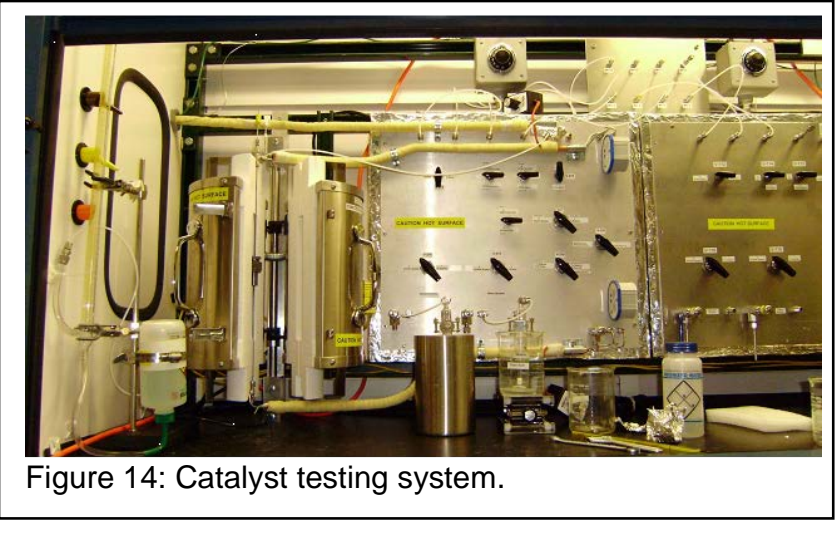


powder or an AAO membrane. The gases are supplied from high pressure gas cylinders using two-stage regulators set to $30 \mathrm{psig}$. The working pressure in the catalyst reaction zone will be maintained at or below 10 psig depending on the flow rate, amount of catalyst, and temperature. In this dual testing system, one system is optimized for testing the catalysts prepared on powder supports, and the other system is optimized for testing the catalysts prepared on AAO supports.

An AAO membrane testing fixture was designed and constructed allowing propane and oxygen to be delivered on opposite sides of the catalytic membrane to evaluate the effect of this asymmetric reactant distribution on the membrane performance (Figure 15). A series of AAO catalytic membranes was prepared by ALD using $\mathrm{V}$-based catalysts for use in the new testing fixture. These membranes had 20$40 \mathrm{~nm}$ pores and the $\mathrm{V}$ catalyst was applied uniformly throughout the pores. These tests

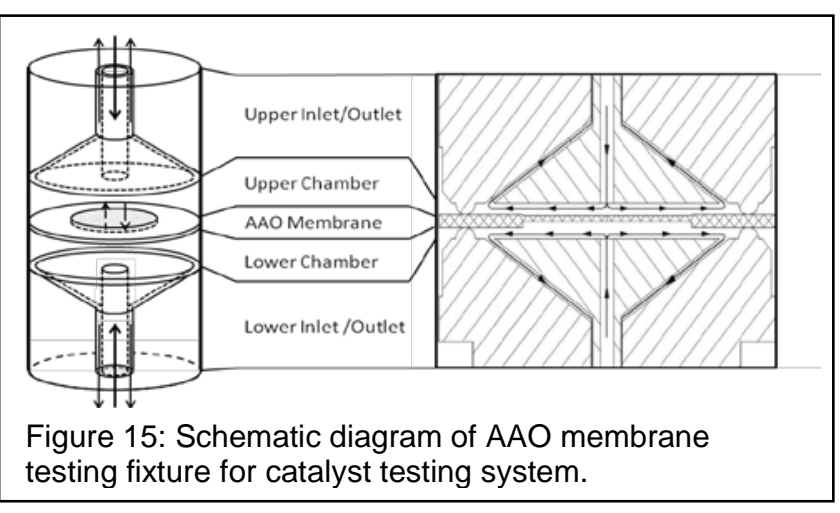
did not indicate any advantage in terms of propylene yield for the asymmetric flow configuration. This is believed to result from rapid diffusion of the reactants through the $20-40 \mathrm{~nm}$ pores. Under the conditions used for these tests, the rapid reactant diffusion apparently negates the effect of delivering the reactants on opposite sides. Smaller membrane pores or higher pressures which reduce this diffusion might enhance the propylene yield. Alternatively, the propylene yield might be enhanced by applying the catalyst at discrete depth locations within the pores using stripe coating.

\subsection{Large Substrate Reactor}

A new deposition chamber for our viscous flow ALD coating system was designed and constructed to allow coating of large format, up to 12 "x18" AAO membranes similar to that shown in Figure 8. This is a scale-up of over 1000x compared to the 0.5" diameter AAO we have used previously. This was a cross flow system with a Kalrez O-ring seal capable of heating to $300^{\circ} \mathrm{C}$ (Figure 16).

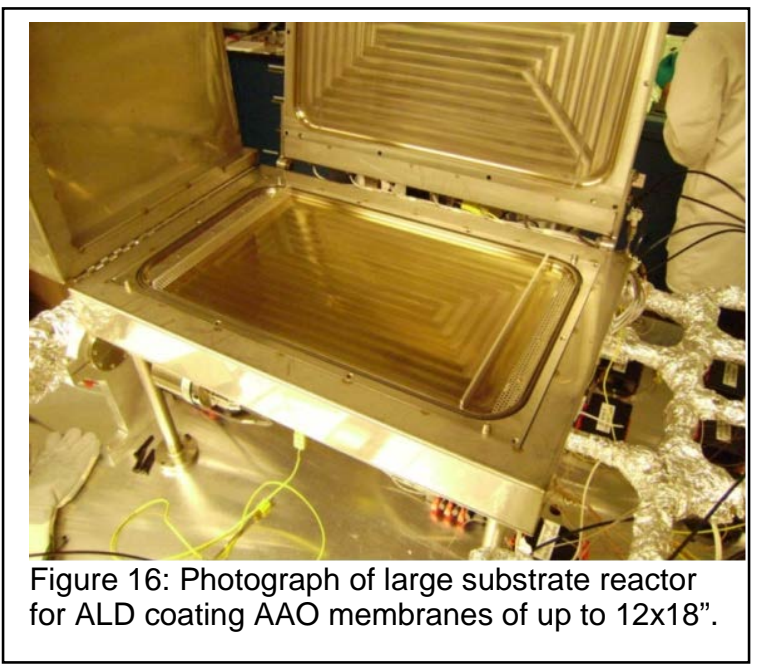




\subsection{Powder Coating Reactor}

To perform the scale up of ALD coating on porous powders such as the silica gel substrate from $1 \mathrm{~g}$ to $1 \mathrm{~kg}$, a powder coating reactor was designed and constructed. The powder coating reactor uses a rotating drum to agitate the powder during coating, and utilizes static dosing of metered quantities of the ALD precursors to maximize precursor utilization (Figure 17). An internal ducted fan circulates the precursor during the doses for more effective coating. The system is integrated with a residual gas analyzer for endpoint detection of the ALD cycles. The system is designed for the batch coating of $10^{4} \mathrm{~m}^{2}$ of high surface area substrates.

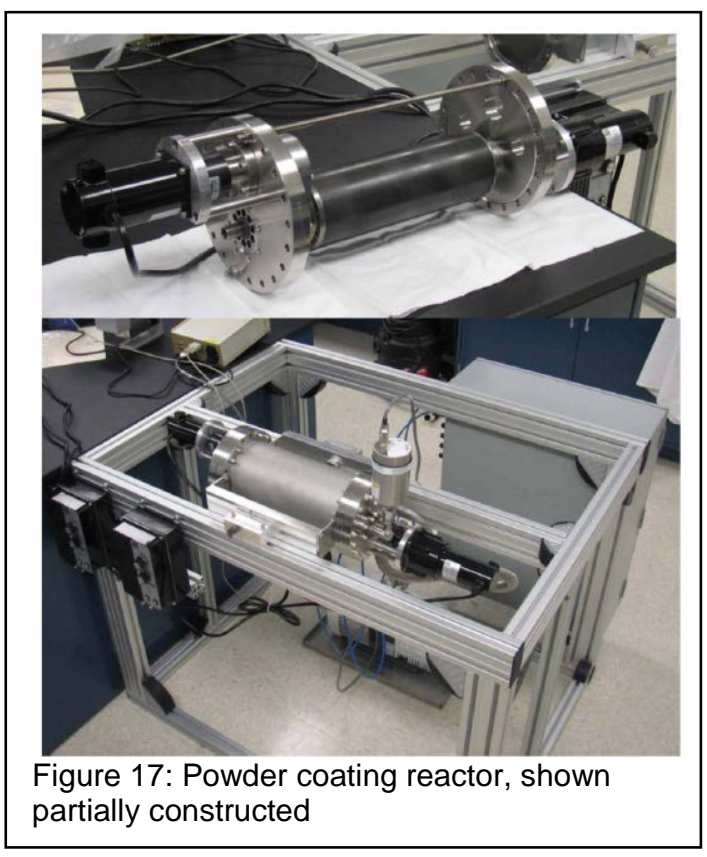

\subsection{Beneq TFS500}

To complete the scale-up of the AAO membrane coating, a commercial ALD coating system (Beneq TFS500) for coating multiple, large-format AAO membranes with catalyst layers was installed and commissioned (Figure 18). Large-format membranes have been coated successfully. We completed the demonstration of coating a large format (8"x8") porous membrane with an ALD layer (bottom right photo in Figure 18). This represents a scale up of $400 x$ in surface area compared to the prototype membranes used for the development work in this project.

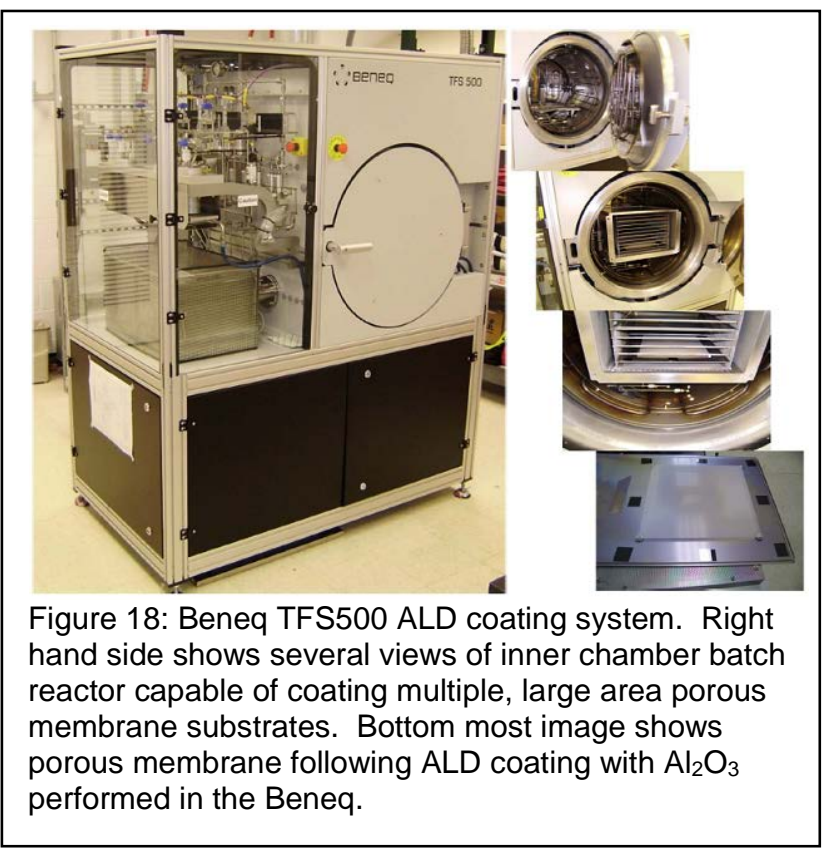




\section{ALD Catalyst Testing}

\subsection{Catalyst Testing at Ineos}

A set of ALD catalysts was prepared at Argonne in which the number of ALD cycles for niobia was varied while keeping constant the loading of vanadia. The goal of this catalyst set was to investigate the necessary thickness of the niobia layer. In addition, a set of ALD catalysts was prepared in which the niobia, vanadia, and tungsten catalysts were blended in a cycle-by-cycle basis. The goal of this set of catalysts was to optimize on the formulation of the niobia/vanadia/tungsten catalysts. These two sets of ALD catalysts were shipped to Ineos for testing. Ineos tested these materials and identified an optimal ordering of the $\mathrm{Nb}$ and $\mathrm{V}$ layers to achieve maximal propylene yield in the oxydative dehydrogenation of propane. These tests also revealed that the effect of the tungsten was minimal. A brief description of these catalysts is given in Table 1, and the test results are summarized in Figure 19. The highest propylene yields were obtained for the 1 cycle $\mathrm{V}$ on 12 cycle $\mathrm{Nb}$ samples prepared on the CP8020 substrate. The CP8020 is a propietary silica gel produced by Ineos having a bimodal pore size distribution.

\begin{tabular}{|l|l|l|l|}
\hline $\begin{array}{c}\text { Argonne } \\
\text { Sample ID }\end{array}$ & $\begin{array}{c}\text { INEOS Calcined } \\
\text { Sample ID }\end{array}$ & \multicolumn{1}{|c|}{ Description } & Support \\
\hline JL_ALD_006 & $22129-72-A$ & 3 cycles V $(3 \%$ V) & CP8020 \\
\hline JL_284 & $22129-72-B$ & 12 cycles Nb, 1 cycle V (1\% V) & CP8020 \\
\hline JL_285 & $22129-72-C$ & 12 cycles Nb, 1 cycle V, 1 cycle W & CP8020 \\
\hline JL_296 & $22129-108-A$ & 12 cycles Nb & CP8020 \\
\hline JE_1260 & $22129-108-B$ & 12 cycles Nb, 1\% V (wet impregnation) & CP8020 \\
\hline JE_1261 & $22129-108-C$ & 12 cycles Nb, 3\% V (wet impregnation) & CP8020 \\
\hline JL_314 & $22195-123-A$ & 12 cycles Nb & Silacycle \\
\hline JL_315 & $22195-123-B$ & 12 cycles Nb, 1 cycle V & Silacycle \\
\hline JL_316 & $22195-123-C$ & 12 cycles Nb, 2 cycles V & Silacycle \\
\hline JL_317 & $22195-123-D$ & 12 cycles Nb, 4 cycles V & Silacycle \\
\hline JL_320 & $22195-123-E$ & 12 cycles Nb, 2 cycle V, "1 ML" Mo (wet impregnation) & Silacycle \\
\hline
\end{tabular}

Table 1: Description of ALD catalysts prepared on silica gel substrates and tested for propane ODH at Ineos 


\section{Propylene Selectivity vs. Propane Conversion}

$0.10-0.15 \mathrm{~g} \mathrm{C}_{3} \mathrm{H}_{8} / \mathrm{g}$ cat $/ \mathrm{hr}, 1.0 \mathrm{O}_{2} / 4.0 \mathrm{~N}_{2} / \mathrm{C}_{3} \mathrm{H}_{8}$

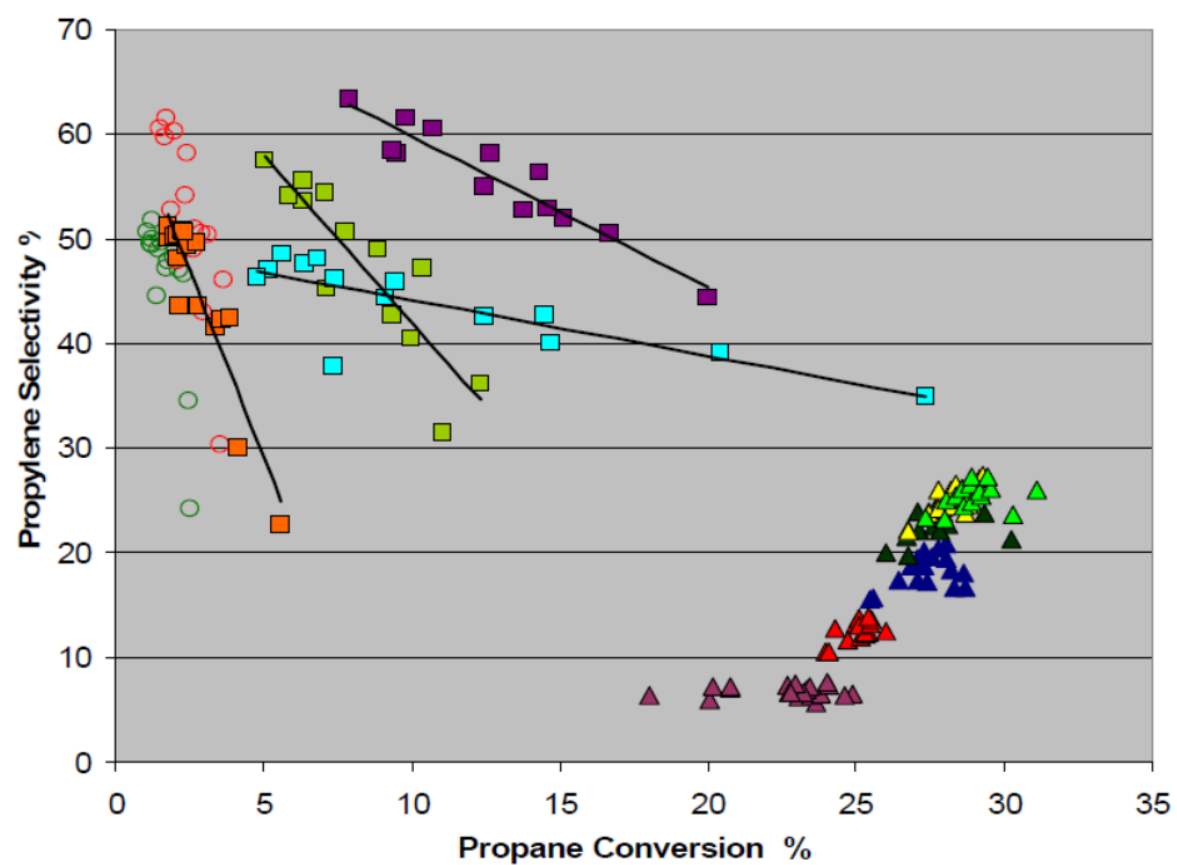

$\Delta 12 \mathrm{Nb}$ ALD, Silicycle

$\Delta 12 \mathrm{Nb}$ ALD, 1 V ALD, Silicycle

$\Delta 12 \mathrm{Nb}$ ALD, 2 V ALD, Silicycle

$\triangle 12 \mathrm{Nb}$ ALD, $4 \vee \mathrm{ALD}$, Silicycle

$\Delta 12 \mathrm{Nb}$ ALD, $2 \vee$ ALD, $1 \mathrm{ML}$ Mo(WI), Silicycle $\triangle 12 \mathrm{Nb}$ ALD, $4 \vee$ ALD, Silicycle, REPEAT

O $\mathrm{SiC}$ control

Silica control

$\square 12 \mathrm{Nb}$ ALD, CP8020

$\square 12 \mathrm{Nb}$ ALD, $1 \% \mathrm{~V}(\mathrm{WI})$, CP8020

$\square 12 \mathrm{Nb}$ ALD, 3\% V (WI), CP8020

$12 \mathrm{Nb}$ ALD, 1 V ALD, CP8020

Figure 19: Summary of testing performed at Ineos of ALD catalysts on silica gel substrates in propane ODH. 


\subsection{Catalyst Testing at Argonne}

An additional set of catalysts was prepared at Argonne to evaluate the effects of the $\mathrm{Nb}_{2} \mathrm{O}_{5}$ support layer thickness, the structure of the silica gel support, the ALD pulse sequence for the $\mathrm{Nb}$ and $\mathrm{V}$ components, as well as the inclusion of ALD Mo to make a three-metal catalyst. These catalysts were tested at Argonne in propane ODH using the catalyst testing system shown in Figure 14, and the results are summarized in Figure 20. One important and surprising finding was that the pore structure of the support has a profound influence on the catalytic behavior. This can be seen in Fig. 20 which shows much higher yields for the catalysts prepared on the Ineos-proprietary CP8020 silica gel which has a bimodal pore size distribution (1.5 and $20 \mathrm{~nm}$ pores), as compared to the commercial Silicycle S10040M which as a nearly identical specific surface area, but a mono-modal pore size distribution (30 nm pores).

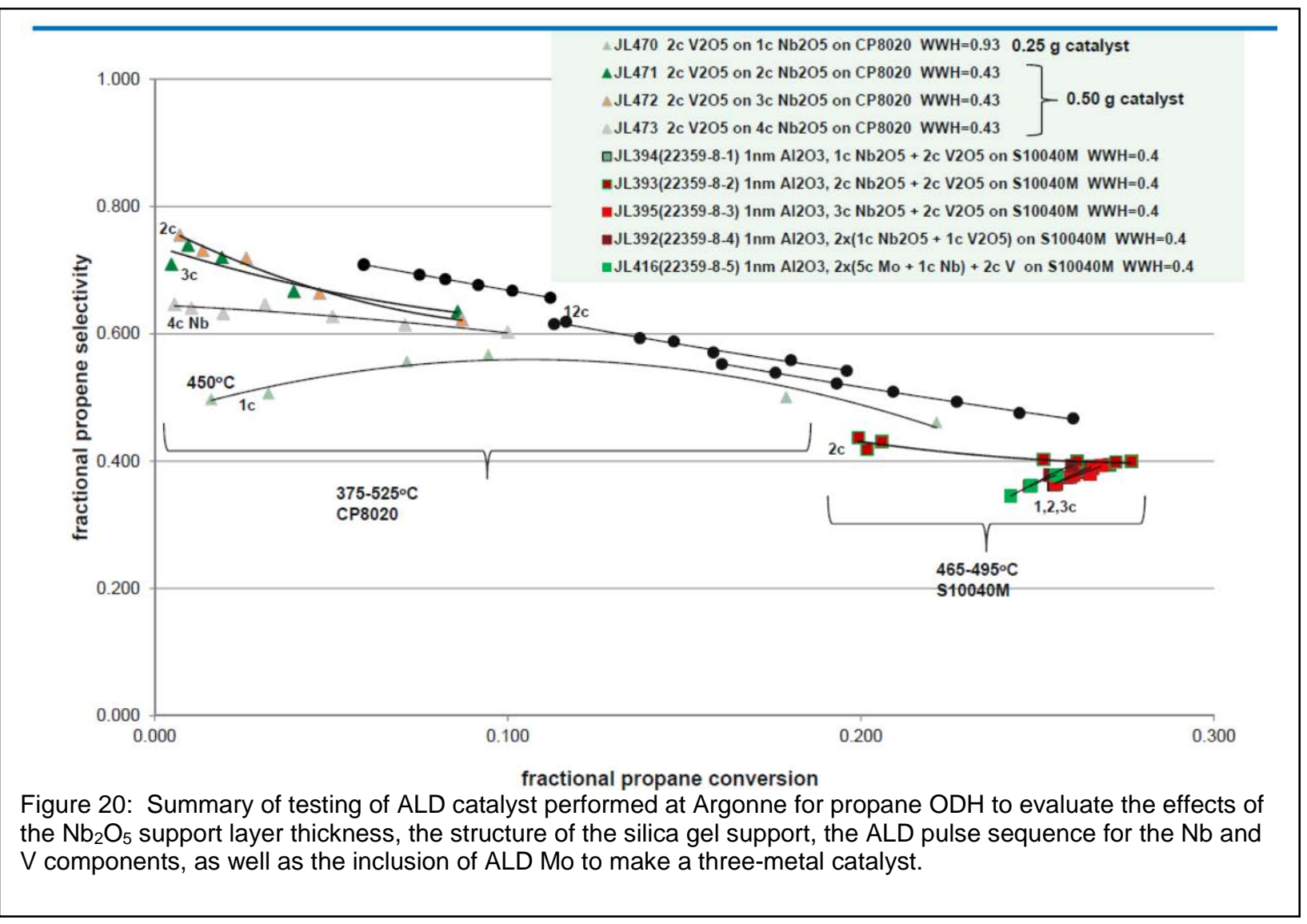


Finally, a pair of identical vanadia catalysts was prepared, with the only difference being that in one case the vanadia was deposited by ALD, and in the second case the vanadia was deposited using conventional incipient wetness impregnation (IWI). These catalysts were tested at Argonne for ethane ODH and the results are shown in Fig. 21. Figure 21 shows that the ethylene yield from the ALD vanadia catalyst is up to $3 x$ higher compared to the IWI catalyst. The much higher yield for the ALD catalyst results from the higher dispersion afforded by ALD. As deposited by ALD, the vanadia species are isolated, thus avoiding the formation of polymers which tend to form the combustion products $\left(\mathrm{CO}\right.$ and $\left.\mathrm{CO}_{2}\right)$ rather than the desired ethylene.

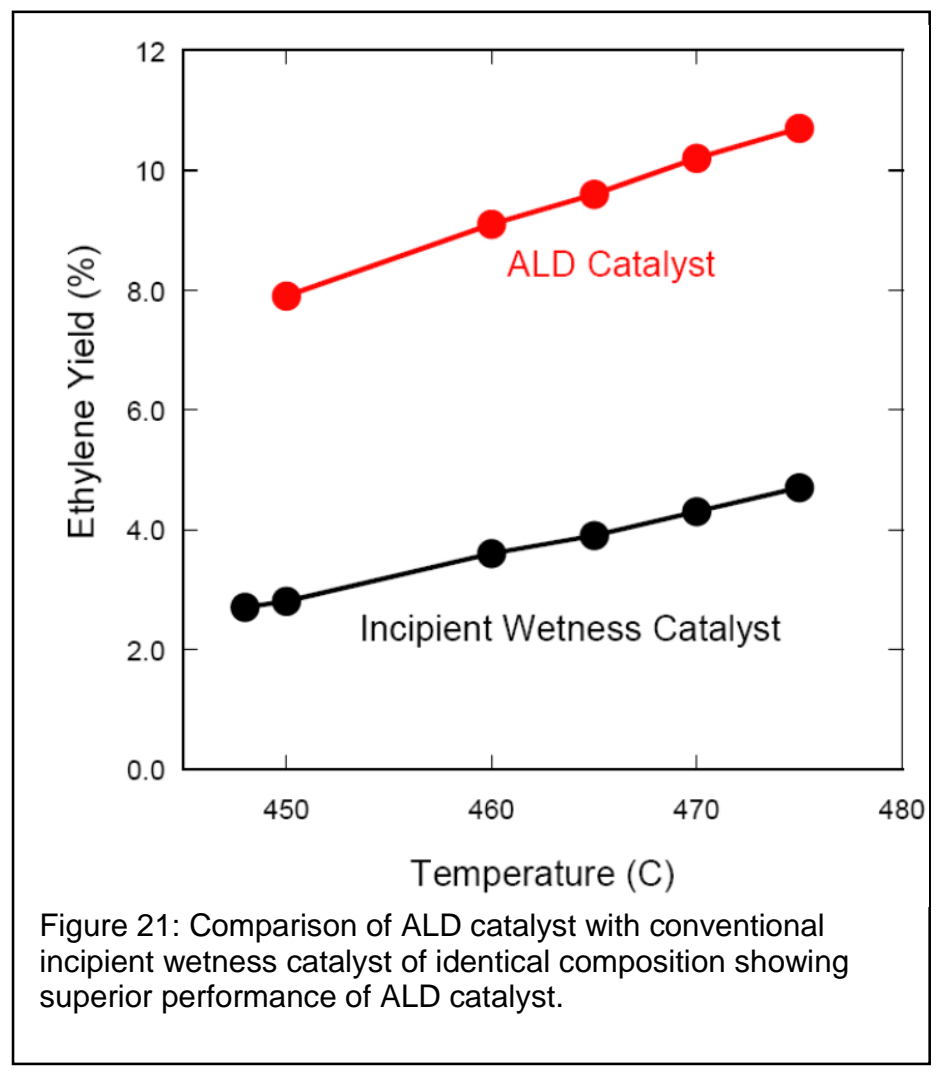


Final Report

Project Number: CPS 11435

August 18, 2014

\section{Accomplishments}

\subsection{Patents}

J. W. Elam, M. J. Pellin, J. A. Libera, P. C. Stair, G. Zajac, and S. Cohen, "Catalyst and Systems Incorporating the Catalyst", US Patent Number 7,972,569, Issued July 5, 2011.

J. W. Elam, J. A. Libera, M. J. Pellin, and P. C. Stair, "Spatially Controlled Atomic Layer

Deposition in Porous Materials", US Patent Number 8,318,248 B2, Issued November 27, 2012.

M. J. Pellin, J. W. Elam and J. N. Hryn, "Catalytic Nanoporous Membranes", ANL-IN-03-055, U.S. Patent Number 7,625,840, Issued December 1, 2009.

\subsection{Publications}

H. Feng, J. W. Elam, J. A. Libera, M. J. Pellin, and P. C. Stair, "Catalytic Nanoliths", Chemical Engineering Science, 64, 560-567, (2009).

P. C. Stair, C. Marshall, G. Xiong, H. Feng, M. J. Pellin, J. W. Elam, L. Curtiss, L. Iton, H. Kung, M. Kung, and H. -H. Wang, "Novel, uniform nanostructured catalytic membranes", Topics in Catalysis, 39, (3-4), 181-186, (2006).

J. W. Elam, J. A. Libera, E. T. Huynh, H. Feng, and M. J. Pellin, "Atomic Layer Deposition of Aluminum Oxide in Mesoporous Silica Gel” J. Phys. Chem. C, 114 (41), 17286-17292, (2010).

T. Y. Shvareva, S. V. Ushakov, A. Navrotsky, J. A. Libera, and J. W. Elam, "Thermochemistry of nanoparticles on a substrate: Zinc oxide on amorphous silica", J. Mater. Res., 23 (7), 19071915, (2008).

J. W. Elam, J. A. Libera, P. C. Stair, and M. J. Pellin, "Spatially Controlled Atomic Layer Deposition in Porous Materials", Appl. Phys. Lett., 91 243105-1 - 243105-3, (2007).

J. A. Libera, J. W. Elam, and M. J. Pellin, "Conformal ZnO Coatings on High Surface Area Silica Gel Using Atomic Layer Deposition", Thin Solid Films, 516, 6158-6166, (2008).

J. W. Elam, J. A. Libera, P. C. Stair, and M. J. Pellin, "Spatially Controlled Atomic Layer Deposition in Porous Membranes", ECS Transactions, 11 (7):177-184 (2007).

M. J. Pellin, P. C. Stair, G. Xiong, J. W. Elam, J. Birrell, L. Curtiss, S. M. George, C. Y. Han, L. Iton, H. Kung, M. Kung, H. -H. Wang, "Mesoporous Catalytic Membranes: Synthetic Control of Pore Size and Wall Composition", Catalysis Letters, 102 (3-4), 127-130 (2005).

J. W. Elam and M. J. Pellin, " $\mathrm{GaPO}_{4}$ Sensors for Gravimetric Monitoring during Atomic Layer Deposition at High Temperatures", Anal. Chem., 77, 3531 (2005). 
J. W. Elam, G. Xiong, C. Y. Han, H. Hau Wang, J. P. Birrell,U. Welp, J. N. Hryn, M. J. Pellin, T. F. Baumann, J. F. Poco, and J. H. Satcher, Jr, "Atomic Layer Deposition for the Conformal Coating of Nanoporous Materials", Journal of Nanomaterials, 2006, 1-5, (2006).

G. Xiong, J. W. Elam, H. Feng, C. Y. Han, H. -H. Wang, L. E. Iton, L. A. Curtiss, M. J. Pellin, M. Kung, H. Kung, and P. C. Stair, "Effect of Atomic Layer Deposition Coatings on the Surface Structure of Anodic Aluminum Oxide Membranes", J. Phys. Chem. B., 109 (29), 14059-14063 (2005).

T. F. Baumann, J. Biener, Y. M. Wang, S. O. Kucheyev, E. J. Nelson, J. H. Satcher, Jr., J. W. Elam, M. J. Pellin, and A. V. Hamza, "Atomic Layer Deposition of Uniform Metal Coatings on Highly Porous Aerogel Substrates", Chem. Mater., 18, 6106-6108, (2006).

P. C. Stair, C. Marshall, G. Xiong, H. Feng, M. J. Pellin, J. W. Elam, L. Curtiss, L. Iton, H. Kung, M. Kung, and H. -H. Wang, "Novel, uniform nanostructured catalytic membranes" , Topics in Catalysis, 39, (3-4), 181-186, (2006).

J. W. Elam, J. A. Libera, M. J. Pellin, A. V. Zinovev, J. P. Greene, and J. A. Nolen, "Atomic layer deposition of W on nanoporous carbon aerogels", Appl. Phys. Lett., 89, 053124, (2006).

"Quantum Chemical Study of Mechanisms for Oxidative Dehydrogenation of Propane on Vanadium Oxide", P. C. Redfern, P. Zapol, M. Sternberg, S. P. Adiga, S. A. Zygmunt, and L. A. Curtiss, Journal of Physical Chemistry B, in press.

\subsection{Presentations}

J. W. Elam, M. J. Pellin, L. A. Curtiss, W. H. Hau, G. K. Krumdick, J. A. Libera, G. W. Zajac, S. A. Cohen and P. C. Stair "Development of Highly Selective Oxidation Catalysts by Atomic Layer Deposition", oral presentation at AIChE Spring Meeting, Houston, TX, April 24, 2007.

J. W. Elam, H. Feng, J. A. Libera, M. J. Pellin, and P. C. Stair, "Nanostructured Catalytic Membranes Synthesized Using Atomic Layer Deposition", poster presentation at AVS $6^{\text {th }}$ International Conference on Atomic Layer Deposition, Seoul, South Korea, July 24-26, 2006.

J. A. Libera, J. W. Elam, J. N. Hryn and M. J. Pellin, "Conformal ZnO Coatings on High Surface Area Silica Gel Using Atomic Layer Deposition", poster presentation at AVS $6^{\text {th }}$ International Conference on Atomic Layer Deposition, Seoul, South Korea, July 24-26, 2006.

$8^{\text {th }}$ International Conference on Atomic Layer Deposition, ALD2008, Brugge, Belgium, "Emerging Applications for ALD in Energy Technologies", J. W. Elam, Invited Seminar, (June, 2008). 
Illinois Institute of Technology Chemistry Colloquium, "Atomic Layer Deposition for the Functionalization of Nanoporous Materials", J. W. Elam, Invited Talk, (Oct., 2007).

Electrochemical Society 211th Meeting, Washington, DC, "Spatially Controlled Atomic Layer Deposition in Porous Supports", J. W. Elam, Contributed Talk, (Oct., 2007).

Chicago Catalysis Club 2007 Spring Meeting, Chicago, IL, "Development of Highly Selective Oxidation Catalysts by Atomic Layer Deposition", J. W. Elam, Contributed Talk (May, 2007).

American Institute of Chemical Engineers Spring National Meeting, Houston, TX, "Development of Highly Selective Oxidation Catalysts by Atomic Layer Deposition", J. W. Elam, Contributed Talk (April, 2007).

"Quantum chemical modeling of catalytic reactions on transition metal oxide surfaces", L. A. Curtiss, seminar at the Chem. Engineering Dept University of Wisconsin, (November 2005).

"Challenges in Modeling of Catalytic Reactions on Transition Metal Oxide Surfaces", L. A. Curtiss, Pacifichem Meeting, Honolulu Dec. 17-21 2005. 


\subsection{Awards}

\section{R\&D100 Award in 2012, "Large-Area Microchannel Plate (MCP)"}

During our DOE ITP-funded project CPS 17784, we developed technology to apply thin film coatings by atomic layer deposition (ALD) inside of nanoporous membranes. The purpose of these coatings was to convert the chemically inert surface of the membrane into a catalytically active surface. For instance, beginning with an anodic aluminum oxide (AAO) membrane with $50 \mathrm{~nm}$ pores, 100 micron thickness, and $1 \mathrm{~cm}^{2}$ surface area, we first deposited 1-10 $\mathrm{nm}$ of $\mathrm{TiO}_{2}$ by ALD to serve as a catalyst support layer, followed by a sub-monolayer of ALD $\mathrm{V}_{2} \mathrm{O}_{5}$. The resulting titania-supported vanadia surface is a highly active catalyst for oxidative dehydrogenation (e.g. propane to propylene). The benefit of the AAO membrane is that the highly uniform pore structure can serve to control precisely the catalyst contact time and consequently tune the selectivity of the catalyst. Moreover, we can precisely control the AAO pore size in the nm-regime by adjusting the thickness of the $\mathrm{TiO}_{2}$ layer, and thereby combine gaseous separations with catalysis in the same porous structure. The initial development work in this catalysis project was performed using our existing bench-scale coating equipment and $\mathrm{cm}$-sized AAO membranes to establish

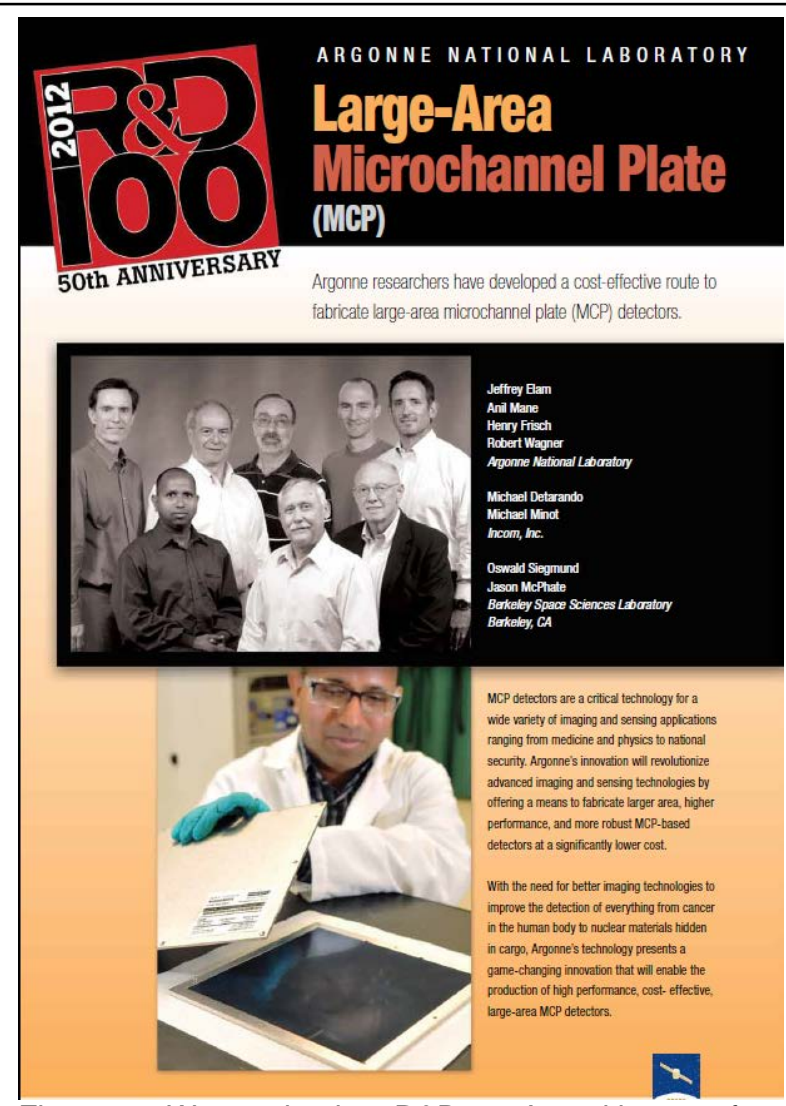

Figure 22: We received an R\&D100 Award in 2012 for our invention, "Large-Area Microchannel Plate (MCP)" based upon the technology and equipment developed in this program.

proof-of-concept. At the end of the project, we commissioned a commercial ALD coating system (Beneq TFS500) to fabricate large area $(20 \times 20 \mathrm{~cm})$ catalytic membranes as a demonstration of scale-up feasibility.

Recently we utilized the technology and equipment developed in our ITP-funded catalysis project for a different application: the fabrication of large area microchannel plate (MCPs). MCPs are solid state electron amplifiers used in image intensifiers (e.g. night vision), mass spectrometry, and particle detection. MCPs are comprised of thin glass plates of micronscale capillaries, each of which acts independently to amplify weak electron signals by $\sim 10,000 x$. Conventional MCP manufacturing is very expensive, and this has limited both the physical size of MCPs (typically $\sim 1$ " diameter) as well as the range of potential applications for these devices. Using our ALD technology, we have developed a new method for manufacturing MCPs. We begin with porous capillary glass arrays fabricated by our industrial partner, Incom, Inc. The capillary glass has a porous structure nearly identical to that of the AAO we used to 
make catalytic membranes, with the exception of larger, micron-scale pores versus the nmscale pores in AAO. Next, we deposit ALD coatings inside of the capillaries to impart the necessary electrical conductivity and electron-multiplying characteristics to the glass surface. Although the composition of the MCP coatings is different compared to the catalytic membranes, the ALD coating process and equipment are the same for both devices. We have successfully scaled-up our ALD manufacturing process to produce 8x8" MCPs which are the largest in the world, and our MCPs have been incorporated into functioning photodetectors. In addition to being up to $5 x$ less expensive compared to conventional MCP manufacturing, the availability of very large MCPs (8x8") opens the door to new applications including: medical imaging, such as positron emission tomography (PET) scanners with 100x faster scanning; national security, including flat-panel neutron detectors that could be used to screen shipping containers or trucks for nuclear materials; large-area particle detectors essential to advancing large-scale, high energy physics experiments. We received an R\&D100 Award in 2012 for our invention, "Large-Area Microchannel Plate (MCP)". This technology has been licensed by Incom, and we are currently engaged in transferring the Argonne MCP technology to Incom.

\section{R\&D100 Award in 2013, "Tunable Resistance Coatings"}

A severe problem hampering the development of novel ion- and electro-optical devices as well as micro-electromechanical systems (MEMS) for use in science and industry is electrostatic charging. For instance, the digital pattern generator (DPG) is a $3 D$, multilayered microelectronic device capable of independently controlling one million electron beams. But the DPG suffers severe performance degradation when its insulating surfaces become electrostatically charged under operation. To solve this problem, Argonne developed Nanocomposite Charge Drain Coatings that can be deposited over complex 3D surfaces, such as the DPG chip, to eliminate electrostatic charging. The Argonne coating has a unique composition and nanostructure that provide unrivaled stability over a wide range of operating conditions and under very high electric fields. These coatings are fabricated using atomic layer deposition (ALD), an economical and production-worthy technology, and have enabled the DPG to achieve excellent performance and a long lifespan. This award

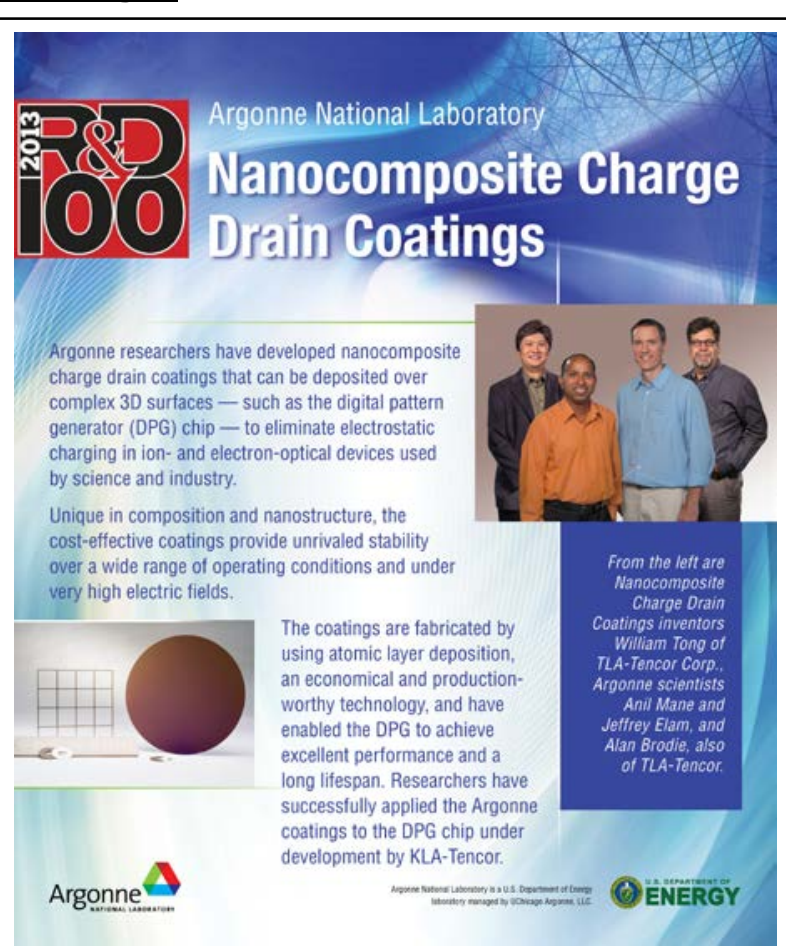

Figure 23: We received an R\&D100 Award in 2013 for our invention, "Charge Drain Coatings" based upon the technology and equipment developed in this program. is based on ALD technology developed under our DOE-ITP project, CPS 17784. In particular, the techniques for tungsten ALD, for blending ALD materials, and for coating complex, non- 
Final Report

August 18, 2014

Project Number: CPS 11435

planar substrates such as the high aspect ratio AAO membranes and the porous silica gel powders were instrumental in the success of the charge drain coating invention. Furthermore, we utilized the equipment and facilities established under our DOE-ITP project to develop and produce the nanocomposite charge drain coatings and to perform the scale-up to larger substrate sizes. 


\section{Argonne}

\section{Energy Systems Division}

Argonne National Laboratory

9700 South Cass Avenue, Bldg. 362

Argonne, IL 60439

www.anl.gov 